\title{
ИСТОЧНИКОВЕДЕНИЕ
}

\section{Родословная бурят хоринского рода харгана: на материале тибетоязычной автобиографии Галсан-Жинбы Дылгырова (1816-1872?)}

\section{Елена Гурбазаровна Батонимаева}

\author{
${ }^{1}$ Институт монголоведения, буддологии и тибетологии СО РАН (д. 6, ул. Сахьяновой, \\ 670047 Улан-Удэ, Российская Федерация) \\ кандидат философских наук, научный сотрудник \\ iD 0000-0001-9180-7229. E-mail: elenabatonimaeva@gmail.com
}

\author{
(C) КалмНЦ РАН, 2021 \\ (C) Батонимаева Е. Г., 2021
}

Аннотация. Введение. В современном бурятском обществе знание своей истории, культуры и языка с каждым годом становится все актуальнее. Вместе с этим растет число людей, интересующихся своей родословной, многие обращаются в различные архивы в поисках своих предков для составления своего генеалогического древа. Свидетельством этому является большая востребованность материалов по родословным бурят, хранящихся в фондах Центра восточных рукописей и ксилографов Института монголоведения, буддологии и тибетологии СО РАН. Цель статьи - дополнить сведения по истории хоринского рода харгана и определить истоки становления Г.-Ж. Дылгырова как видного религиозного просветителя XIX в. При написании статьи были использованы текстологический, сравнительно-исторический и историко-биографический методы. Mатериалом для данной статьи послужили сведения из автобиографии Г.-Ж. Дылгырова, написанной на тибетском языке между 1864-1872 гг. и опубликованной ксилографическим способом в Цугольском дацане. Родословная Г.-Ж. Дылгырова приведена в первой главе его автобиографии, поэтому прочитать ее мог только узкий круг людей, владеющих тибетским языком. Результаты. Родословная состоит из 8 поколений, включая самого Г.-Ж. Дылгырова, и уходит вглубь на более чем 150 лет, восходит к предку по имени Шоногулэг, жившему на рубеже XVII-XVIII вв. Большой интерес вызывают сопровождающие родословную родовые легенды и предания. Изучение родословной раскрывает происхождение этнонима баатаржан - родового ответвления хоринского рода харгана, а также позволяет дополнить сведения по истории органов местного самоуправления бурят до первой трети XIX в. Кроме того, данная работа может послужить материалом для проведения генеалогических исследований.

Ключевые слова: автобиография, буряты, хори-буряты, родословные, зайсан, Галсан-Жинба Дылгыров, тибетский язык

Благодарность. Работа выполнена в рамках государственного задания «Памятники письменности народов России и Внутренней Азии на восточных языках и архивные 
документы XVIII - нач. XXI вв. в контексте межцивилизационного взаимодействия» (номер госрегистрации: 121031000302-9).

Для цитирования: Батонимаева Е. Г. Родословная бурят хоринского рода харгана: на материале тибетоязычной автобиографии Галсан-Жинбы Дылгырова (1816-1872?) // Монголоведение. 2021. Т. 13. № 2. С. 328-340. DOI: 10.22162/2500-1523-2021-2-328340

\title{
The Genealogy of Khargana Clan of Khori-Buryats in the Light of Tibetan Autobiography of Galsan-Zhinba Dylgirov
}

\section{Elena G. Batonimaeva ${ }^{1}$}

${ }^{1}$ Institute for Mongolian, Buddhist and Tibetan Studies of the Siberian Branch of the RAS (6 Sakhyanova St., 670047 Ulan-Ude, Russian Federation)

Cand. Sc. (Philosophy), Research Associate

iD 0000-0001-9180-7229. E-mail: elenabatonimaeva@gmail.com

(C) KalmSC RAS, 2021

(C) Batonimaeva E. G., 2021

\begin{abstract}
Introduction. In the modern Buryat society, the knowledge of one's own history, roots, culture, and language is becoming increasingly important. There is also a growing interest in genealogical research as many have started to search for data about their ancestors and their family trees in various archives. To illustrate, one may mention an increasing number of requests made for materials on the lineage and pedigrees of Buryats kept in the Center of Oriental Manuscripts and Xylographs of the Institute for Mongolian, Buddhist, and Tibetan Studies of the Siberian Branch of the RAS. The aims of the present article are, firstly, to add to the data on the Khargana clan of Khori Buryats and, secondly, to investigate the background of Galsan-Zhinba Dylgirov (1816-1872?), an outstanding Buryat religious enlightener of the nineteenth century. The research is based on textological, comparativehistorical and historical-biographical methods. Data. The article draws on the evidence contained in Dylgirov's autobiography written in Tibetan in 1864-1872 and xylographed in the Tsugol Datsan. Dylgirov's lineage is cited in the first chapter of the book and could be read only by few of those who were literate in Tibetan. Results. The lineage goes back to eight generations, including Dylgirov himself, and covers over 150 years. The origin of the family associates with the ancestor known as Shonoguleg who lived at the turn of the eighteenth century. Of particular interest are also legends and stories that supplement the family history. The examination of the lineage sheds light on the origin of the ethnonym Baatarzhan, a branch of the Khargana clan. Also, the family history contains new data on the Buryat self-governing administration before the first third of the nineteenth century. Clearly, the data of Dylgirov's autobiography may be useful for further genealogical research.
\end{abstract}

Keywords: autobiography, Buryats, Khori-Buryats, genealogy, zaisan, Galsan-Zhinba Dylgirov, Tibetan language

Acknowledgements. The research was carried out within the state assignment: 'Monuments of scripts of the peoples of Russia and Inner Asia in oriental languages and archival documents of the XVIII-th and early XXI-th centuries in the context of intercivilizational interaction, № 121031000302-9'.

For citation: Batonimaeva E. G. The Genealogy of Khargana Clan of Khori-Buryats in the Light of the Tibetan Autobiography of Galsan-Zhinba Dylgirov. Mongolian Studies (Elista). 2021; 13(2): 328-340. (In Russ.). DOI: 10.22162/2500-1523-2021-2-328-340 


\section{Введение}

В настоящее время в бурятском обществе наблюдается рост интереса к своей истории, культуре и языку, одновременно с этим растет число бурят, занимающихся поиском своих родственных связей и предков. В начале XX в. профессор Б. Петри писал, что «почтенному и уважающему себя буряту стыдно не знать всех своих предков подряд, начиная от отца и кончая родоначальника» [Петри 1925: 42]. В начале XXI в. многие буряты для восстановления своих родословных вынуждены обращаться в различные архивы. Большая востребованность материалов по родословным бурят, хранящихся в фондах Центра восточных рукописей и ксилографов Института монголоведения, буддологии и тибетологии СО РАН (далее - ИМБТ СО РАН), выявила необходимость создания цифрового корпуса генеалогических источников.

О. С. Ринчинов пишет: «генеалогические знания сохраняют огромное значение как способы поддержания исторической памяти, идентификации людей и сообществ. Зафиксированные образцы генеалогического знания - родословные являются памятниками историко-культурного наследия» [Ринчинов 2020: 102].

В Центре восточных рукописей и ксилографов ИМБТ СО РАН в личном архиве известного фольклориста и этнографа С. П. Балдаева содержится наибольшее количество единиц хранения по родословным бурят. Более 60 лет С. П. Балдаев собирал материалы по фольклору, этнографии, культуре и истории бурят. В 1970 г. вышла его монография «Родословные легенды и предания бурят. Булагаты и эхириты» [Балдаев 1970].

В предисловии к изданию А. И. Уланов писал, что «объем публикации не позволил включить все предания и легенды, записанные у знатоков старины в разных местах, но имеющие одинаковое содержание», «генеалогические таблицы по многим родам публикуются частично, с сокращениями ответвлений» [Балдаев 1970: 4-5]. Вторая часть («Родословные легенды и предания бурят. Забайкальские буряты») была опубликована совместно с переизданием первой части в 2012 г. [Балдаев 2012].

Бурятские исторические хроники и родословные на старомонгольской письменности как источники по истории бурят были исследованы Ц. Б. Цыдендамбаевым. Вторая часть его монографии посвящена лексическому своеобразию, орфографическим и грамматическим особенностям языка бурятских исторических хроник и родословных [Цыдендамбаев 1972].

Изучение родословных бурят тесно связано с вопросами этнической истории бурят. Б. 3. Нанзатов и М. М. Содномпилова справедливо замечают, что «с проблемой происхождения бурят неизбежно сталкивается каждый, кто изучает родословную своей семьи» [Нанзатов, Содномпилова 2016б: 5].

О функции рода и важности знания родословной в культово-обрядовой сфере жизни бурят написано в целом ряде работ и статей [Батоева и др. 2002; Скрынникова 2010; Сыденова 2017; и др.].

\section{Материалы и методы}

В данной статье представлена родословная Галсан-Жинбы Дылгырова, бурята хоринского рода харгана. Г.-Ж. Дылгыров ${ }^{1}$ (1816-1872?) - представитель

${ }^{1}$ Его тибетское имя - Агван Галсан Лубсан Жинба (тиб. ngag dbang blo bzang skal bzang spyin pa), санскритский псевдоним - Вагиндра Сумати Калпа Бхадра Дана (санскр. Vagindra Sumati Kalba Bhadra Dana). 


\section{Источниковедение}

бурятского буддийского духовенства XIX в., автор более 30 комментариев и переводов крупных буддийских сочинений с тибетского на монгольский язык, второй настоятель Цугольского дацана² [Ванчикова 2000: 88].

Письменное наследие Г.-Ж. Дылгырова становилось объектом исследования в работах Р. Е. Пубаева [Пубаев 1981], Отгонбаатара [Отгонбаатар 1995], Б. Д. Баяртуева [Баяртуев 1997], Е. Р. Шубиной [Шубина 2014], Д. С. Жамсуевой [Жамсуева 2001], Ц. П. Ванчиковой и М. В. Аюшеевой [Ванчикова, Аюшеева 2016] и других.

Материалом для написания данной статьи послужили сведения из первой главы автобиографии Г.-Ж. Дылгырова [Автобиография 1864-1872]. О существовании автобиографии Г.-Ж. Дылгырова впервые сообщается в «Летописи баргузинских бурят», подготовленной к изданию отечественными востоковедами А. И. Востриковым и Н. Н. Поппе [Востриков, Поппе 1935: 47].

В своей работе «Тибетская историческая литература» А. И. Востриков упоминает ее среди тибетских намтаров ${ }^{3}$ видных лам Бурятии [Востриков 1962: 115].

В 1998 г. автобиография Г.-Ж. Дылгырова была переведена на монгольской язык и опубликована ученым Л. Тэрбишем [Тэрбиш 1998]. Краткое описание основного содержания автобиографии Г.-Ж. Дылгырова дано в двух статьях Ц. П. Ванчиковой: «О двух первых настоятелях Цугольского дацана» [Ванчикова 1999] и «Тибетские и монгольские источники о деятельности первых настоятелей Цугольского дацана» [Ванчикова 2000].

Автобиография Г.-Ж. Дылгырова написана на тибетском языке между 1864-1872 гг. и опубликована ксилографическим способом в Цугольском дацане. Текст написан на 55 листах размером 43,5 × 8,5 см, на одном листе размещено 5 строк. Текст расположен на обеих сторонах листов. Он разделен на 6 глав, и для каждой главы использована раздельная пагинация. Каждая глава имеет собственное название. Начинается каждая из них заголовком «Достоверное личное изложение моих деяний», который является общим для всех глав, и его можно принять за общее название всей автобиографии. Название каждой главы, вступительная и заключительная части глав написаны в стихотворной форме. В конце каждой главы автобиографии указана дата ее составления. Первая глава написана на 6 листах, на 1 и 6-м листах текст расположен на одной стороне. В данной главе повествуется о жизни Г.-Ж. Дылгырова до 13-летнего возраста [Ванчикова 2000: 89-90].

\section{Родословная хоринского рода харгана}

Наиболее распространенной у бурят была устная форма генеалогических знаний, а с распространением монгольской письменности в XVII в. формируется традиция письменной фиксации родословных. Сохранившиеся бурятские родословные в основном относятся к XIX в. и началу XX в., представлены большей частью в рукописных списках. Ц. Б. Цыдендамбаев пишет, что «имеющиеся у частных лиц списки хроник и генеалогических таблиц переходили из рук в руки, внимательно читались и нередко заучивались наизусть в той их части, которая

${ }^{2}$ Цугольский дацан (тиб. bkra shis chos 'phel gling) - буддийский монастырь, расположен в с. Цугол Могойтуйского района Забайкальского края. Основан в 1826 г.

${ }^{3}$ Намтар (тиб. rnam thar) - жанр тибетской агиографической литературы. Намтары представляют собой биографии буддийских учителей, написанные ими самими, их учениками или авторами позднейшего времени [Востриков 1962: 109-116]. 
касалась истории рода и родословной ветви данного круга читателей» [Цыдендамбаев 1972: 9]. В этом отношении родословная Г.-Ж. Дылгырова выделяется из всех сохранившихся бурятских родословных XIX в. Она входит в первую главу его автобиографии, написанной на тибетском языке. Поэтому прочитать ее мог только узкий круг людей, владеющих тибетским языком. Родословная состоит из 8 поколений, включая самого Г.-Ж. Дылгырова, и уходит вглубь на более чем 150 лет, восходя к предку по имени Шоногулэг, жившему на рубеже XVII-XVIII вв. [Автобиография 1864-1872: 1r-6r].

Таблища 1. Родословная Галсан-Жинбы Дылгырова

[Table 1. Genealogy of Ven. Galsan-Zhinba Dylgirov] ${ }^{4}$

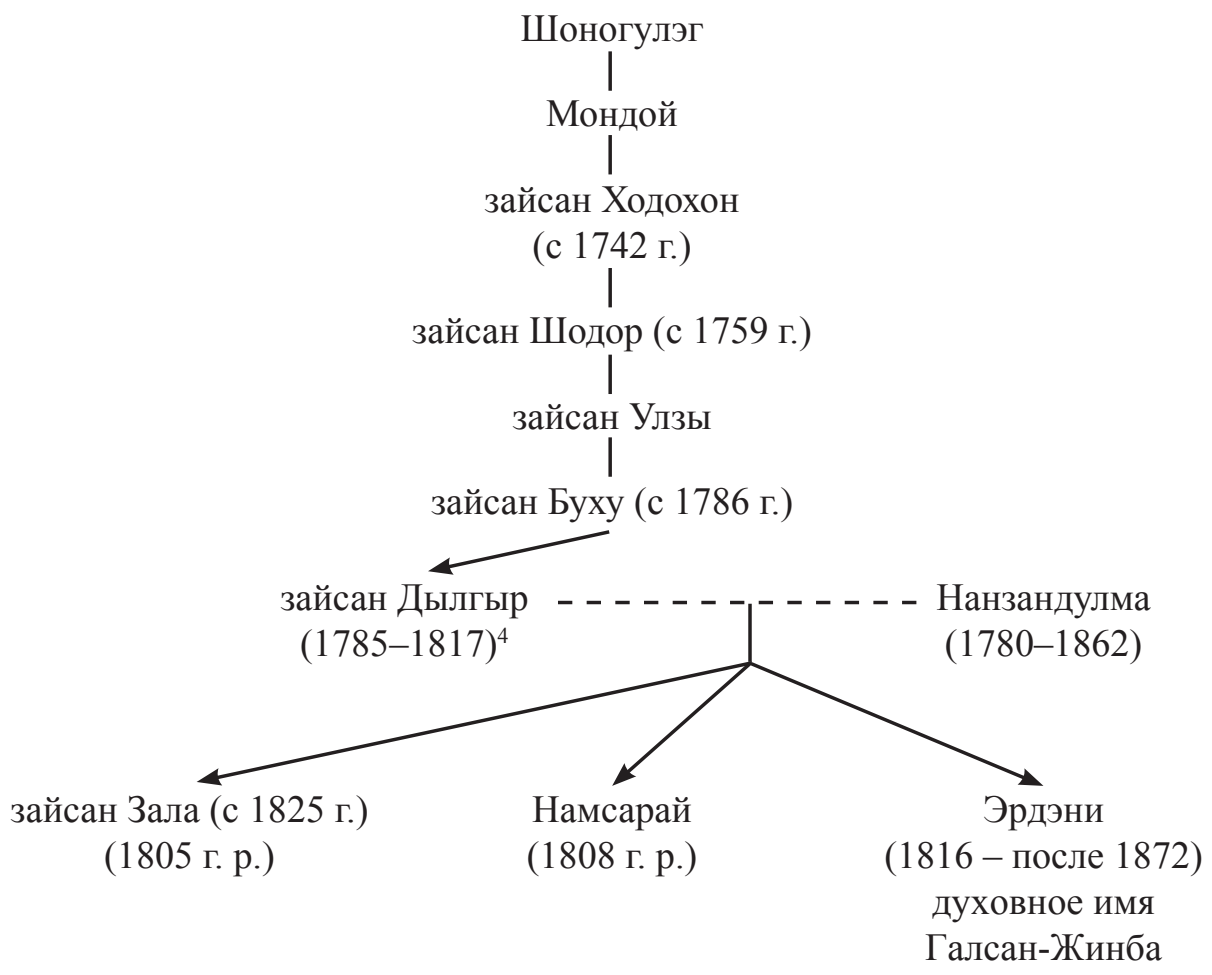

Г.-Ж. Дылгыров писал, что родился в 1816 г. в долине речки Судунтуй

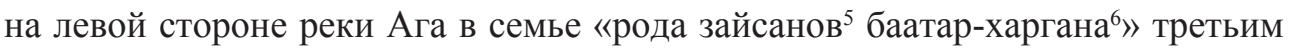

${ }^{4}$ Г.-Ж. Дылгыров в 1-й главе своей автобиографии сообщил дату своего рождения и год смерти отца Дылгыра, а в 5-й главе сообщил дату смерти своей матери Нанзандулмы. Эти даты позволили нам вычислить годы их жизни. Даты рождения и смерти Дылгыровым указаны в соответствии с тибетским летосчислением, которым буряты пользовались до первой трети ХХ в.

5 Зайсан - титул, известный у монголов еще в юаньский период. Происходит от кит. 宰相 zăixiàng 'канцлер', ‘великий визирь'. В XVIII в. засул стоял во главе хотона, т. е. группы аилов с населением в 10-12 семейств. Шуленга стоял во главе объединения хотонов (примерно 4-6 хотонов), называемых холбоном и табином. Во главе нескольких холбонов стоял зайсан [Бурятские летописи 1995: 100].

${ }^{6}$ Тиб. rigs dzas sang rus $p$ A thor har kan. 


\section{Источниковедение}

сыном у отца зайсана Дылгыра 7 и у матери Нанзандулмы [Автобиография 1864-1872: 1r]. При рождении ему было дано имя Эрдэни. Старших братьев зовут Зала и Намсарай. Своих предков Дылгыров перечислил по восходящей линии: 1) отец Дылгыр, 2) отец Дылгыра - дед зайсан Буху, 3) отец Буху прадед зайсан Улзы, 4) отец Улзы - зайсан Шодор, 5) отец Шодора — зайсан Ходохон, 6) отец Ходохона - Мондой, 7) отец Мондоя - Шоногулэг. Родословная сопровождена родовыми легендами и преданиями, а также письменными документами [Автобиография 1864-1872: 1r-2r].

К хоринским родам относятся 11 родов: галзуд, хуацай, хубдуд, гушад, шарайд, харгана, худай, бодонгуд, хальбин, саган и батанай ${ }^{8}$ [Бурятские летописи 1995: 5]. Свой род принято называть вместе с родовым ответвлением, которые хоринские буряты называют $x х Y Y p^{9}$ - 'кукур, кость, ответвление рода, патронимия' [Цыдендамбаев 1972: 85].

Ц. Б. Цыдендамбаев сообщает, что по материалам Читинского отряда диалектологической экспедиции 1965-1966 гг. было выявлено 9 хухуров рода харгана хоринских бурят: моотган, хухэнэт, хоран, онхот, тангут, абахан, баряхан, баторжан, хоодой. В ходе экспедиции были зафиксированы родословные хухуров моотган, хухэнэт, хоран, онхот и тангут. Родословные же остальных четырех хухуров не удалось разыскать [Цыдендамбаев 1972: 94].

Б. 3. Нанзатов и М. М. Содномпилова при исследовании этнического состава и территории расселения хоринских бурят в XIX в. выявили 13 хухуров рода харгана: хоохэй, хоодой, моотгон, онхот, хоран, тангуд, шигудай, байтай, хушуун, барюухай, батанай, тангад, баатаржан [Нанзатов, Содномпилова 2016а: 39]. Они же в своем исследовании уже этнического состава агинских бурят ${ }^{10}$ XIX в. выяснили, что среди агинских бурят рода харгана встречаются хухуры: хоохэй, моотгон, баатаржан, абга, баитай [Нанзатов, Содномпилова 2017: 30]. Указанный в автобиографии род «баатар-харагана», скорее всего, есть родовое ответвление баторжан/баатаржан хоринского рода харгана.

Происхождение этнонима рода харгана ${ }^{11}$, по мнению Ц. Б. Цыдендамбаева, «связано с первоначальным местом его обитания, обильно поросшим кустарником караганы, поэтому и получившим свое название по этому признаку. В Бурятии и Монголии имеется ряд мест с этим названием» [Цыдендамбаев 1972: 203].

${ }^{7}$ Имена на бурятском языке отличаются от написания на русском. Имя Дылгыр по-бурятски пишется Дэлгэр и в переводе означает «изобильный», «благодатный». Возможные написания имени на русском: Дылгыр, Дылыгыр, Дылгир, Дэлгэр и прочее. Поскольку у бурят не существовало фамилий, то в официальных документах до начала XX в. в качестве фамилии записывали имя отца. Имя Галсан-Жинбы Дылгырова (Дылгирова) по-бурятски пишется Дэлгэрийн Галсанжинба.

8 Здесь и далее названия родов и родовых ответвлений даны в авторских редакциях.

${ }^{9}$ Бур. хүхүYр. В научной литературе встречаются написания «кукур» и «хухур». В бурятско-русском словаре дается следующее толкование слова хүхүҮр: кукур (подразделения малых племен. Например, кукуры кубдутского малого племени, относящегося к большому племени хори) [БРС 2010, 2: 507].

${ }^{10}$ После выделения Агинской степной думы в 1839 г. из Хоринской степной думы значительная часть хори-бурят получила новую территориальную привязку и стала именоваться агинскими бурятами [Нанзатов, Содномпилова 2016а: 30].

${ }^{11}$ Бур. харгана - 1. карагана; кусты, кустарник; 2. харгана (один из одиннадцати хоринских родов) [БРС 2010, 2: 405]. 


\section{Монголоведение • Mongolian Studies • 2021 • T. 13 • № 2}

Согласно легенде из родословной Г.-Ж. Дылгырова, этноним родового ответвления баторжан/баатаржан берет свое название от предка в 7-м поколении Шоногулэга ${ }^{12}$, который жил на рубеже XVII-XVIII вв. был смелым и храбрым и прославился в народе как баamap ${ }^{13}$, т. е. богатырь. Ц. Б. Цыдендамбаев полагает, что «кукуры получили свои наименования по именам сыновей главы рода, независимо от того, являлись ли они родными или чужеродными» [Цыдендамбаев 1972: 203]. Можно предположить, что Шоногулэг как глава ответвления рода был более известен под именем Баатар, и его потомки стали называть себя «баатаржанами». Так, сведения из родословной Г.-Ж. Дылгырова можно будет отнести к одному из источников, уточняющих появление этнонима баторжан/баатаржан.

Ц. П. Ванчикова отмечает, что в семье Г.-Ж. Дылгырова «были сильны традиции книжности, еще у Ходохон-зайсана дома имелись буддийские книги» [Ванчикова 2000: 89]. Согласно семейному преданию, предок Ходохон встретился в Монголии с Богдо-гэгэном и преподнес ему 100 голов скота. Он исповедовал учение Будды, приобрел и читал 12 томов сутр праджняпарамиты «Юм» ${ }^{14}$ на монгольской письменности. Семейная традиция читать буддийские книги берет начало от него. Из этого следует вывод, что уже до середины XVIII в. предки Дылгырова получали домашнее образование, и ко второй половине XIX в. пять поколений семьи умели читать и писать на монгольском письме. Галсан-Жинба писал, что отец Дылгыр любил читать буддийские тексты, успел обучить монгольскому письму своих старших сыновей Залу и Намсарая, но умер от болезни в возрасте 32 лет, когда Эрдени не было еще и года. Поэтому старший брат Зала взял на себя отцовскую обязанность учителя и обучил монгольскому письму своего младшего брата, когда тому исполнилось 5 лет. Семейная традиция получения домашнего образования с малых лет способствовала тому, что Г.-Ж. Дылгыров много занимался переводческой и просветительской деятельностью.

Самый ранний письменный документ, упоминаемый в автобиографии, также связан с именем предка Ходохона, а именно это патент о назначении зайсаном, который он получил 14-го февраля 1742 г. из Нерчинска ${ }^{15}$. В общей сложности,

${ }^{12}$ Имя Шоногулэг означает «волчонок», состоит из двух слов шоно 'волк', ‘волчий’ [БРС 2010, 2: 617] и гүлгэн ‘щенок' [БРС 2010, 1: 231].

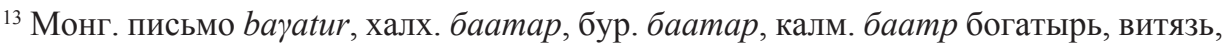
герой; (ист.) багатур (глава рода или племени эпохи раннего феодализма, один из титулов феодализирующейся степной аристократии) [ЭСМЯ 2015, 1: 67]. Бур. баатар 1. богатырь, батор, батыр, герой; 2. богатырский; смелый, мужественный, отважный; героический, доблестный [БРС 2010, 1: 98-99]. Бурятское имя Баатар по-русски пишется как «Батор».

14 «Юм» сутры праджняпарамиты - учение о пустоте и бодхичитте. В тексте намтара сообщается, что эти 12 томов «Юма» сейчас находятся в монастыре Дэчэн Чойнхорлинг (тиб. bde chen chos 'khor gling). Предположительно, говорится о Гунэйском дацане, построенном в 1802 г. в с. Гунэй Агинского района.

15 Тиб. nir shu'i yA mon «Нерчинский ямэнь». Ямэнь - общественно-политический термин, означающий «присутственное место», «учреждение» или «канцелярию». В русских исторических и дипломатических документах сложились два варианта написания этого слова: ямэнь и ямынь. Происходит от кит. 衙门 yámen - «приказ», «присутствие». 


\section{Источниковедение}

приводя свою родословную, Дылгыров сообщает о четырех документах на получение звания зайсана. Из них три документа датированы XVIII в., и они хранились в семье на момент написания автобиографии. Предки Ходохон и Шодор получили свои звания из Нерчинска в 1742 г. и 1759 г. соответственно. Дед зайсан Буху получил письмо о пожаловании звания в 1786 г. уже из Баргузина. Четвертый патент на наследственное звание зайсана был получен старшим братом Залой Дылгыровым в 1825 г. из Зун-Харганатской инородной управы.

На примере родословной Г.-Ж. Дылгырова можно проследить историю органов местного самоуправления бурят до первой трети XIX в. Зайсаны были известны у монголов еще в юаньский период. После проведения границы между Российской империей и цинским Китаем в 1727 г. территории Прибайкалья и Забайкалья вошли в состав России. Российская империя переняла существовавшую форму социальной самоорганизации бурят: «у бурят существовали Степные конторы как органы самоуправления, сугланы — как высшая законодательная власть, тайши, зайсаны, шуленги, совмещавшие в себе руководителей родов и административную должность» [История Агинской 2017: 6].

После присоединения к России свои патенты на должности буряты стали получать от русских властей. По-видимому, предок Ходохон был первым в роду, кто получил свое звание зайсана от русских властей в 1742 г. из Нерчинска. Еще Н. Н. Поппе и А. И. Востриков замечали, что «некоторые хоринские нойоны в конце XVIII в. стали получать патенты на свое звание из Баргузина, тогда как до этого времени они получали их из Нерчинска» [Востриков, Поппе 1935: 47].

В летописи баргузинских бурят Цэдэбжаба Сахарова сообщается о том, что «вначале был уездный город. В это время хоринские буряты находились в ведении Баргузинского округа» [Бурятские летописи 1995: 180]. Действительно, Баргузин получил статус уездного города Нерчинской области в 1783 г., но уже в 1822 г. этот статус был упразднен. И получается, что дед Дылгырова, зайсан Буху, получил свое письмо о пожаловании звания зайсана «22 июня 1786 года указом императрицы России из Баргузинского ямэня» ${ }^{16}$ [Автобиография 1864-1872: 1r-2r].

Согласно Уставу об управлении инородцев 1822 г. М. М. Сперанского, устанавливалось трехступенчатое управление сибирскими кочевыми народами: Степная дума, инородная управа, родовое управление. Так в 1824 г. была учреждена Хоринская Степная дума ${ }^{17}$, которая первоначально объединяла 11 родов. Однако отдаленность от главной конторы привела к разделению трех хоринских родов - харгана, кубдут и хуацай - на две части: восточные (зYYн) и западные (баруун). В итоге в Хоринской Степной думе было учреждено 14 инородных управ по числу родов: Галзотская, Барун-Харганатская, Зун-Харганатская, Барун-Хоацайская, Зун-Хоацайская, Барун-Кубдутская, Зун-Кубдутская,

${ }^{16}$ Тиб. gnam lo chig stong bdun brgya gya drug pa zla ba e yu ni tshes nyer gnyis la/ rgya ser gong ma chen mo rgyal mo’i bka' lung gis par ko cing gi yA mon nas.

${ }^{17}$ Во главе думы стоял тайша (иначе главный родоначальник), а при нем состояли заседатели (прежние зайсаны и шуленги) и головы инородных управ и писарь. Во главе инородной управы стоял голова, при котором состояли выборные. Во главе родового управления стоял староста, имевший одного или двух помощников [Бурятские летописи 1995: 35]. 
Батанайская, Шарайтская, Ботонгутская, Ходайская, Гучитская, Цаганская, Хальбинская и Курбинское отдельное общество [История Агинской 2017: 6-8].

По уставу 1822 г. у лиц, управлявших внутри родов в звании зайсанов, шуленг и засулов, их звания как официальные были упразднены, но сохранились как почетные. И, таким образом, Зала Дылгыров ${ }^{18}$ получил свое почетное звание зайсана в 1825 г. из Зун-Харганатской инородной управы ${ }^{19}$. Почти сразу с учреждением Хоринской Степной думы встал вопрос об учреждении отдельной Степной думы для группы хоринских родов, кочевавших на территории Нерчинского округа. Так в 1839 г. была учреждена Агинская Степная дума в составе 6 инородных управ: Цугольская, Бырке-Цугольская, Могойтуевская, Шолотуевская, Калинская, Тутхалтуевская [История Агинской 2017: 9-10]. В документе «Именного списка всех инородческих родоначальников Нерчинского округа по ведомству Агинской Степной Думы за 1847 г.» сообщается, что Зала Дылгыров с 1 марта 1843 г. являлся головой Цугольской инородной управы [История Агинской 2019: 39].

В своей монографии Ц. Б. Цыдендамбаев замечал, что «в бурятских исторических сочинениях с большой тщательностью указываются номера и даты документов, когда речь заходит об отведении бурятам земель для кочевий, о так называемых патентах на почетные звания и должности, о каких-либо деловых распоряжениях вышестоящих властей и т. п.» [Цыдендамбаев 1972: 128-129]. По мнению Ц. Б. Цыдендамбаева, это было связано с тем, что «в тех исторических условиях им важно было с документами на руках подтвердить права бурят, как тогда писали, на „породные земли или высочайше отведенные земли“, права бурятских родоначальников на привилегии и т. д. Иными словами, бурятских летописцев того времени прежде всего интересовала официально-юридическая, а не научная сторона постановки вопроса» [Цыдендамбаев 1972: 129].

Юки Конагая и Д. Ц. Бороноева пишут, что «отличительной особенностью бурятских летописей является „документальность“ изложения, особенно начиная с событий, происходивших после вхождения Бурятии в состав Российской империи» [Конагая, Бороноева 2006: 70].

В намтаре Г.-Ж. Дылгырова все даты даны в тибетском летосчислении, за исключением дат, связанных с официальными документами от администрации русских властей, в том числе и документами о назначении предков главами рода. Это говорит о том, что Г.-Ж. Дылгыров был хорошо знаком с современными ему бурятскими сочинениями, в частности с историческими хрониками и генеалогиями. Поэтому в его родословной присутствует та же «документальность» изложения, что была характерна для бурятских исторических хроник.

18 Зала Дылгыров вместе с другими должностными лицами Агинской Степной думы был обвинителем в следственном деле о взяточничестве заседателя Нерчинского земского суда Посельского. Зала Дылгыров русского языка не знал, был женат, имел троих сыновей и одну дочь, занимался хлебопашеством и скотоводством, жил в урочище Турга [Дамешек, Жалсанова, Курас 2013: 387].

19 Зун-Харгана - административное деление рода харгана, появившееся в 1824 г. В тексте автобиографии тибетское har ka na g.yon gyi yA mon дословно переводится как «левого харгана ямэнь». В бурятском языке слово зүүн имеет значения «левый» и «восточный» [БРС 2010, 1: 418-419]. 


\section{Источниковедение}

\section{Выводы}

Родословная хори-бурята рода харгана Г.-Ж. Дылгырова приведена в первой главе его автобиографии, написанной на тибетском языке между 1864-1872 гг. и опубликованной ксилографическим способом в Цугольском дацане [Автобиография 1864-1872]. Родословная записана в традиционной форме повествования по восходящей линии и состоит из 8 поколений, восходит к предку Шоногулэгу, жившему на рубеже XVII-XVIII вв. Сопровождающая родословную легенда может служить одним из источников происхождения этнонима баторжан/ баатаржан.

Традиции получения домашнего образования и чтения книг на монгольском и тибетском языках способствовали тому, что Г.-Ж. Дылгыров посвятил свою жизнь проповеднической, переводческой и издательской деятельности. Исследование родословной бурятской степной знати показывает ее ценность для изучения истории органов местного самоуправления бурят в XIX в.

Данные родословной Г.-Ж. Дылгырова, связанные с письменными документами о получении его предками звания зайсанов, отражают подлинные события, поскольку подтверждаются сведениями из бурятских летописей и архивными документами, что свидетельствует об их исторической достоверности и возможности их использования для научной реконструкции отдельных этапов истории разных этнических групп бурят. Большую ценность этим данным придает то, что три патента о назначении главами рода, которые, скорее всего, до нашего времени не сохранились, датированы XVIII в.

\section{Источники}

Автобиография 1864-1872- rang spyod rang gsal rang gi thems yig Автобиография Г.-Ж. Дылгырова (ксилогр. на тиб. яз., 1864-1872 гг., Цугольский дацан) // Личный архив Ц. П. Ванчиковой. 55 л. размером 43,5 × 8,5 см.

\section{Sources}

Reliable Personal Narrative of My Deeds: Autobiography of Ven. Galsan-Zhinba Dylgyrov. In: Personal files of Ts. P. Vanchikova. 55p. (In Tib.)

\section{Литература}

Балдаев 1970 - Балдаев С. П. Родословные предания и легенды бурят. Булагаты и эхириты. Улан-Удэ: Бурят. кн. изд-во, 1970. 363 с.

Балдаев 2012 - Балдаев С. П. Родословные предания и легенды бурят. Улан-Удэ: Издво Бурят. гос. ун-та, 2012. 710 с.

Батоева и др. 2002 - Батоева Д. Б., Галданова Г. Р., Николаева Д. А., Скрынникова Т. Д. Обряды в традиционной культуре бурят. М.: Вост. лит., 2002. 222 с.

Баяртуев 1997 - Баяртуев Б. Д. Галсан-Жинба Дылгыров (1816-?) // Российские монголоведы (XVIII - начало ХХ вв.). Улан-Удэ: Изд-во БНЦ СО РАН, 1997. С. 36-39.

БРС 2010, 1 - Бурятско-русский словарь: в 2 тт. / сост. Л. Д. Шагдаров, К. М. Черемисов. Т. І. А-Н. Улан-Удэ: Изд-во ОАО «Республиканская типография», 2010. 636 с.

БРС 2010, 2 - Бурятско-русский словарь: в 2 тт. / сост. Л. Д. Шагдаров, К. М. Черемисов. Т. ІІ. О-Я. Улан-Удэ: Изд-во ОАО «Республиканская типография», 2010.708 с.

Бурятские летописи 1995 - Бурятские летописи / сост. Ш. Б. Чимитдоржиев, Ц. П. Ванчикова. Улан-Удэ: Бурят. Ин-т обществ. наук СО РАН, 1995. 199 с.

Ванчикова 1999 - Ванчикова Ц. П. О двух первых настоятелях Цугольского дацана // Проблемы традиционной культуры народов Байкальского региона. Улан-Удэ: Издво БНЦ СО РАН, 1999. С. 92-94. 


\section{Монголоведение • Mongolian Studies • 2021 • T. 13 • № 2}

Ванчикова 2000 - Ванчикова Ц. П. Тибетские и монгольские источники о деятельности первых настоятелей Цугольского дацана // Культура Центральной Азии. Вып. 4. Улан-Удэ: Изд-во БНЦ СО РАН, 2000. С. 85-101.

Ванчикова, Аюшеева 2016 - Ванчикова Ц. П., Аюшеева М. В. «Сокровищница трех учений» — новый источник по истории Цугольского дацана // Вестник Бурятского научного центра Сибирского отделения Российской академии наук. 2016. № 4 (24). C. $68-77$.

Востриков 1962 - Востриков А. И. Тибетская историческая литература / отв. ред. Ю. Н. Рерих, предисл. Н. П. Востриковой. М.: ИВЛ, 1962. 427 с.

Востриков, Поппе 1935 - Востриков А. И., Поппе Н. Н. Летопись баргузинских бурят. Тексты и исследования. Труды Института востоковедения. Т. VIII. М.; Л.: Изд-во АН CCCP, 1935. 75 c.

Дамешек, Жалсанова, Курас 2013 - Дамешек Л. М., Жалсанова Б. Ц., Курас Л. В. История органов местного самоуправления бурят в XIX - начале XX в. Иркутск: Изд-во ИГУ, 2013. 503 с.

Жамсуева 2001 - Жамсуева Д. С. Агинские дацаны как памятники истории культуры. Улан-Удэ: Изд-во БНЦ СО РАН, 2001. 170 с.

История Агинской 2017 - История Агинской Степной думы в документах Государственного архива Республики Бурятия (1839-1904 гг.). Ч. І: Формулярные и послужные списки должностных лиц Агинской степной думы [сб. док., перечень док.] / авт.-сост.: Б. В. Базаров, Б. Ц. Жалсанова, Л. В. Курас / науч. ред. Н. Н. Крадин. Иркутск: Оттиск, 2017. 676 с.

История Агинской 2019 - История Агинской Степной думы в документах Государственного архива Республики Бурятия (1839-1904гг.). Ч. ІІ: Делопроизводственные документы Агинской Степной думы [сб. док., перечень док.] / авт.-сост.: Б. В. Базаров, Б. Ц. Жалсанова, Л. В. Курас / науч. ред. Н. Н. Крадин. Иркутск: Оттиск, 2019. 368 с.

Конагая, Бороноева 2006 - Юки Конагая, Бороноева Д. Ц. Бурятские летописи как исторические источники по этнической идентичности бурят // Культура Центральной Азии: письменные источники. Вып. 7. Улан-Удэ: Изд-во БНЦ СО РАН, 2006. C. $68-104$.

Нанзатов, Содномпилова 2016а - Нанзатов Б. 3., Содномпилова М. М. Хоринская Степная дума в XIX веке (этнический состав и расселение хоринских бурят) // Вестник Бурятского научного центра Сибирского отделения РАН. 2016. № 3 (23). С. 28-40.

Нанзатов, Содномпилова $2016 б$ - Нанзатов Б. З., Содномпилова М. М. Этническая идентичность бурят и исторические мифы в контексте этногенеза // Вестник Восточно-Сибирского государственного института культуры. 2016. № 2 (11). С. 5-12.

Нанзатов, Содномпилова 2017 - Нанзатов Б. З., Содномпилова М. М. Агинские буряты в XIX в.: этнический состав и расселение // Вестник Бурятского научного центра Сибирского отделения РАН. 2017. № 2 (26). С. 28-35.

Отгонбаатар 1995 - Отгонбаатар Р. Один из гарчиков Д. Галсанжинбы // Средневековая культура Центральной Азии: письменные источники. Улан-Удэ: Изд-во БНЦ CO PAH, 1995. C. 28-30.

Петри 1925 - Петри Б. Э. Программа для собирания преданий по истории заселения Прибайкалья бурятами // Бурятиеведение. 1925. № 1. С. 41-44.

Пубаев 1981 - Пубаев P. E. «Пагсам-чжонсан» - памятник тибетской историографии XVIII века. Новосибирск: Наука, 1981. 307 с.

Ринчинов 2020 - Ринчинов О. С. Бурятские родословные в цифровом пространстве: вопросы формирования и анализа корпуса генеалогических источников // Вестник Бурятского научного центра Сибирского отделения. 2020. № 1 (37). С. 102-110.

Скрынникова 2010 - Скрынникова Т. Д. Функции рода у бурят (конец XIX-XX вв.) // Новый исторический вестник. 2010. № 4 (26). С. 11-18. 


\section{Источниковедение}

Сыденова 2017 - Сыденова Р. П. Культовая практика в бурятской улусной общине во второй половине XIX - начале XX вв. // Исторические, философские, политические и юридические науки, культурология и искусствоведение. Вопросы теории и практики. 2017. № 3-1 (77). С. 153-155.

Цыдендамбаев 1972 - Цыдендамбаев Ц. Б. Бурятские исторические хроники и родословные. Улан-Удэ: Бурят. кн. изд-во, 1972. 662 с.

Шубина 2014 - Шубина Е. P. «Магтал двенадцати деяний светлейшего спасителя Будды» Галсанджинбы Дылгырова // Mongolica-XIII. СПб.: ИВР РАН, 2014. С. 65-70.

ЭСМЯ 2015 - Санжеев Г. Д., Орловская М. Н., Шевернина 3. В. Этимологический словарь монгольских языков: в 3 тт. Т. І. А-Е. / гл. ред. Г. Д. Санжеев; ред. Л. Р. Концевич, В. И. Рассадин, Я. Д. Леман. М.: ИВ РАН, 2015. 224 с.

Тэрбиш 1998 - Тэрбиш Л. Бичгийн их хүн дуун хөрвүүлэгч Д. Галсанжинбын намтар (= Автобиография великого литератора, переводчика Галсан Жинбы). Улаанбаатар: [б. и.], 1998. 95 с.

\section{References}

Baldaev S. P. Genealogical Tales and Legends of Buryats. Ulan-Ude: Buryat State University, 2012. 710 p. (In Russ.)

Baldaev S. P. Genealogical Tales and Legends of Buryats: Bulagats and Ehirits. Ulan-Ude: Buryatia Book Publ., 1970. 363 p. (In Russ.)

Batoeva D. B., Galdanova G. R., Nikolaeva D. A., Skrynnikova T. D. Rituals in Buruat Traditional Culture. Moscow: Vostochnaya Literatura, 2002. 222 p. (In Russ.)

Bayartuev B. D. Galsan-Zhinba Dylgirov (1816-?). In: Mongolists of Russia, $18^{\text {th }}$ to Early $20^{\text {th }}$ Centuries. Ulan-Ude: Buryat Scientific Center (Sib. Branch of RAS), 1997. Pp. 36-39. (In Russ.)

Bazarov B. V., Zhalsanova B. Ts., Kuras L. V. (comps.) History of the Aginsk Steppe Duma: Documents from the State Archive of the Republic of Buryatia, 1839-1904. Part I: Records of Service. N. Kradin (ed.). Irkutsk: Ottisk, 2017. 676 p. (In Russ.)

Bazarov B. V., Zhalsanova B. Ts., Kuras L. V. (comps.) History of the Aginsk Steppe Duma: Documents from the State Archive of the Republic of Buryatia, 1839-1904. Part II: Documents of Management and Record Keeping. N. Kradin (ed.). Irkutsk: Ottisk, 2019. 368 p. (In Russ.)

Chimitdorzhiev Sh. B., Vanchikova Ts. P. (comps.) Buryat Chronicles. Ulan-Ude: Buryat Institute of Social Sciences (Sib. Branch of RAS), 1995. 199 p. (In Russ.)

Dameshek L. M., Zhalsanova B. Ts., Kuras L. V. History of Buryat Local Government Bodies, $19^{\text {th }}-$ Early $20^{\text {th }}$ Centuries. Irkutsk: Irkutsk State University, 2013. 503 p. (In Russ.)

Konagaya Yu., Boronoeva D. Ts. Buryat chronicles as historical sources on ethnic identity of Buryats. In: Culture of Central Asia: Written Sources. Ulan-Ude: Buryat Scientific Center (Sib. Branch of RAS), 2006. Vol. 7. Pp. 68-104. (In Russ.)

Nanzatov B. Z., Sodnompilova M. M. Buryat ethnic identity and historical myths in the context of ethnogenesis. Vestnik Vostochno-Sibirskogo gosudarstvennogo instituta kul'tury. 2016. No. 2 (11). Pp. 5-12. (In Russ.)

Nanzatov B. Z., Sodnompilova M. M. The Aginsk Buryats in the $19^{\text {th }}$ century: ethnic composition and settlement. Bulletin of the Buryat Scientific Center of the Siberian Branch of the RAS. 2017. No. 2 (26). Pp. 28-35. (In Russ.)

Nanzatov B. Z., Sodnompilova M. M. The Qori Steppe Duma in the $19^{\text {th }}$ century (ethnic composition and settlement of Qori Buryats). Bulletin of the Buryat Scientific Center of the Siberian Branch of the RAS. 2016. No. 3 (23). Pp. 28-40. (In Russ.)

Otgonbaatar R. One of D. Galsan-Zhinba's garchags. In: Medieval Culture of Central Asia: Written Sources. Ulan-Ude, 1995. Pp. 28-30. (In Russ.) 
Petri B. E. How Buryats populated the Baikal Region: a historical legends collecting program. Buryatievedenie. 1925. No. 1. Pp. 41-44. (In Russ.)

Pubaev R. E. Pag sam jon zang: A $18^{\text {th }}$-Century Monument of Tibetan Historiography. Novosibirsk: Nauka, 1981. 307 p. (in Russ)

Rinchinov O. S. Buryat lineages in the digital world: formation and analysis of the Corpus of Genealogical Sources. Bulletin of the Buryat Scientific Center of the Siberian Branch of the RAS. 2020. No. 1 (37). Pp. 102-110. (In Russ.)

Sanzheev G. D., Orlovskaya M. N., Shevernina Z. V. Etymological Dictionary of Mongolic Languages. In 3 vols. Vol. I: A - E. G. Sanzheev et al. (eds.). Moscow: Institute of Oriental Studies (RAS), 2015. 224 p. (In Mong. and Russ.)

Shagdarov L. D., Cheremisov K. M. (comps.) Buryat-Russian Dictionary. In 2 vols. Vol. 1: A-H. Ulan-Ude: Respublikanskaya Tipografiya, 2010. 636 p. (In Bur. and Russ.)

Shagdarov L. D., Cheremisov K. M. (comps.) Buryat-Russian Dictionary. In 2 vols. Vol. 2: O-Я. Ulan-Ude, 2010. 708 p. (In Bur. and Russ.)

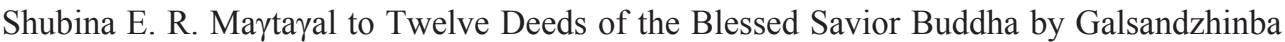
Dylgyrov. In: Mongolica-XIII. St. Petersburg: Institute of Oriental Manuscripts (RAS), 2014. Pp. 65-70. (In Russ.)

Skrynnikova T. D. Functions of the clan among the Buryats (the end XIX - XX c.). The New Historical Bulletin. 2010. No. 4 (26). Pp. 11-18. (In Russ.)

Sydenova R. P. Cult practice in the Buryat ulus community in the second half of the XIX - the early XX century. Historical, Philosophical, Political and Law Sciences, Culturology and Study of Art. Issues of Theory and Practice. 2017. No. 3-1 (77). Pp. 153-155. (In Russ.)

Terbish L. D. Galsan-Zhinba: Autobiography of the Great Writer and Translator. Ulaanbaatar, 1998. 95 p. (In Mong.)

Tsydendambaev Ts. B. Buryat Historical Chronicles and Genealogies: A Historical and Linguistic Study. Ulan-Ude: Buryatia Book Publ., 1972. 662 p. (In Russ.)

Vanchikova Ts. P. About two founding abbots of Tsugol Datsan. In: Peoples of the Baikal Region: Issues of Traditional Culture. Ulan-Ude: Buryat Scientific Center (Sib. Branch of RAS), 1999. Pp. 92-94. (In Russ.)

Vanchikova Ts. P. Tibetan and Mongolian sources mentioning activities by the two founding abbots of Tsugol Datsan. In: Culture of Central Asia: Written Sources. Ulan-Ude: Buryat Scientific Center (Sib. Branch of RAS), 2000. Vol. 4. Pp. 85-101. (In Russ.)

Vanchikova Ts. P., Ayusheeva M. V. 'Treasury of Three Doctrines' - a new written source on the history of the Tsugol Datsan. Bulletin of the Buryat Scientific Center of the Siberian Branch of the RAS. 2016. No. 4 (24). Pp. 68-77. (In Russ.)

Vostrikov A. I. Tibetan Historical Literature. Yu. Roerich (ed.). Moscow: Vostochnaya Literatura, 1962. 427 p. (In Russ.)

Vostrikov A. I., Poppe N. N. Chronicles of Barguzin Buryats: texts and studies. Ser.: Proceedings of the Institute of Oriental Studies. Vol. VIII. Moscow; Leningrad: USSR Academy of Sciences, 1935. 75 p. (In Russ.)

Zhamsueva D. S. Datsans of Aga Buryatia as Monuments of Cultural History. Ulan-Ude: Buryat Scientific Center (Sib. Branch of RAS), 2001. 170 p. (In Russ.) 